\title{
EDITORIAL
}

\section{To the cell and molecular biology, cell physiology and pathology, cell morphology, structure and cytochemistry - the struggle for publication}

\author{
Karel Smetana \\ Institute of Hematology and Blood Transfusion. Prague, Czech Republic
}

Received $27^{\text {th }}$ September 2005.

Published online $16^{\text {th }}$ November 2005.

\begin{abstract}
Summary
The editorial boards with responsible reviewers in scientific journals might play a very important role and should be of a great help for authors. It is a reasonable hope that the journals with such reviewers might be very much respected as well as and highly evaluated without overestimation of the impact factor.
\end{abstract}

Key words: biomedicine - publication - impact factor - future development

Based on endless studies it is known that the cell is the fundamental structural and functional unit of all living organisms. It is also clear that the cell itself is also a unit which consists of both basic organelles and frequently of very specialized components. The former are necessary for its life and the latter for specialized functions. At present, we are in the era of molecular biology with a variety of scientific disciplines dealing with its specialized areas, such as molecular pathology, molecular genetics, molecular pharmacology and many others. It

Karel Smetana, Institute of Haematology and Blood Transfusion, U Nemocnice, 12800 Praha 2 - Nové Město, Czech Republic 品 karel.smetana@uhkt.cz would be very difficult to find in biomedical research a single field in which molecular biology is not used as a very useful approach for solving newly and continuously appearing topics and problems. It should also be added that the very rapidly growing methodical base represents a great support for all of the continuously developing disciplines of molecular biology. Among the variety of changes in the scientific organizations, such development is also reflected in the creation of new journals and by the changing content of those which have been published for many years. Some of them have changed not only the content of articles accepted for publication but also changed or modified the title (see the list of biomedical journals in databases).

On the other hand, even at the present time it seems to be also clear that different levels of 
both intercellular and intracellular organization still need and will in the future need very detailed knowledge of the morphology of all components present not only within but also outside the cell, including various tissue constituents. Such knowledge is continuously required for complementation of new findings in molecular and cell biology. Morphological observations under various conditions may provide new knowledge, especially when they are achieved with new or older improved methodical approaches. In certain areas of research or diagnostic investigations such observations cannot be replaced by other approaches. Recently, it seems that specialized functional morphology or cytochemistry represents a unique tool for studies dealing with the various state of the single cell. In addition, new morphological methods are on the way to contributing to molecular biology and its specialized disciplines. It should be mentioned here that large molecules or molecular complexes under defined conditions are visible with the microscope including their pathological configurations and locations. In addition, the observations achieved in situ are necessary for understanding the biology of the "normal as well as abnormal cell" especially at the single cell level.

Today's situation is very much resembling the time when morphology and biochemistry were competing and frequently antagonistic. Such competition, however, ended in mutual complementation since the morphologist was interested in the composition and function of the structure investigated by himself and the biochemist was interested in the organization of the analyzed cell structure. Moreover, frequently, the biochemist required the morphological control of the purity of analyzed cells or their isolated fractions. A similar development can now be seen in the relationship between morphology and molecular biology. The cooperation of these two basic scientific approaches can be summarized in the understanding of cell biology and functions including cell biology and the disturbed function of abnormal cells or the cell composition of various organs and organisms. Thus it seems to be natural that molecular biology has penetrated even to morphologically oriented institutions dealing with anatomy, histology or pathological anatomy and histology. Similarly, new morphological procedures and observations, particularly at the single cell level are used in departments or institutes dealing mainly with molecular biology. On the other hand, in certain journals such cooperation is very rare and frequently depends on the journal orientation and editorial board as well as reviewers, regardless of the quality of the manuscript sent for editorial consideration. It is known that in many cases reports dealing with new phenomena are rejected because of the main methodical frequently morphological - approach of the authors for whom it is very difficult to find the proper journal. Then after some period of time it appears that the rejected manuscripts contained new facts which were described and verified by others or were useful for molecular and cell biologists. Even some very well known scientists were faced with such situations. The best way of preventing this situation it would be to accept all manuscripts which do not show serious mistakes or dubious observations. However, the cost of publications and other factors are unfortunately against this approach.

At present, it seems likely that some articles, mainly those using the morphological approach published in not-impacted journals or journals with a low impact factor might be underestimated. Such articles might be not only interesting but also important in respect of future developments in cell biology and cell pathology. It may be helpful to respect them as equals when the scientific competence of their authors is evaluated by supervising authorities. On the other hand, in numerous institutions the supervisors respect the impact factor of the journal containing the published article rather than its content. Such evaluation of published articles might be inadequate in respect to their content and importance disregarding their orientation and disciplines (see e.g. Ojasoo et al. 2002, Kurmis 2003, Rogers 2003, Brahler et al. 2004). However, frequently, it seems to be simpler because the evaluation of the scientific contributions represents one of the most difficult activities. It should be also mentioned here that the orientation of authors determines and limits the type of journals for the publication of the results of their scientific efforts. The impact factor of such journals is frequently low because of the narrow and limited circle of interested researchers and other reasons (see Cathey and Kader 2004). However, in contrast, some journals without an impact factor are very much respected since they are widely distributed and evaluated highly by a large circle of 
readers (see e.g. Medical Science Monitor). In addition, some journals (see e.g. Hematology) with widely recognized and respected reviewers must wait several years to be included to generally recognized bases of scientific journals and to receive the impact factor.

It would be very easy to document all above discussed topics by known and published examples. I am sure that all of researchers are familiar with and also are occasionally more or less disgusted after rejection of their manuscripts. Fortunately, it does not mean that they will not continue in their efforts to enrich present knowledge in the field. Most of them are enthusiastic and will continue hoping that the results of their efforts will be useful and respected sooner or later in the future. The editorial boards with responsible reviewers in scientific journals might play a very important role and should be of a great help for authors. Badly written manuscripts, even with good science, have less chance of being accepted and published (San Francisco Edit 2005). Thus the role of reviewers should be useful not only for the journal but also for authors. It seems to be likely that authors would appreciate the constructive and useful comments of informed reviewers who would know how to improve the manuscript and future possible approaches to the studied topic. It is a reasonable hope that the journals with such reviewers might be very much respected as well as and highly evaluated without overestimation of the impact factor.

\section{REFERENCES}

Brahler E., Beutel E., Decker O.: Deep impactevaluation in the science. Soz. Prventivmed. 49:10-14, 2004.

Cathey J.T., Kader A.: The impact of the impact factor. Saudi Med. J. Suppl. S37, 2004.

Kurmis A.P.: Understanding the limitations of the journal impact factor. J. Bone Joint Surg. Am. 85A:2449-2454, 2003.

Ojasoo T., Maisonneuve H., Matillon Y.: The impact factor of medical journals, a bibliometric Indicator to be handled with care. Presse Med. 31:775-781, 2002.

Rogers L.F.: Impact factor: myths and realities. Ann. Acad. Med. Singapore 32:429-432, 2003

San Francisco Edit: Ten steps to writing an effective abstract. E-mail message, 2005. 